\title{
Article \\ Students' Attitudes and Competences in Modeling Using 3D Cartoon Toy Design Maker
}

\author{
Yu Fu ${ }^{1}$, Dongliang Zhang ${ }^{2}$ and Hao Jiang ${ }^{2, *}$ \\ 1 School of Design and Architecture, Zhejiang University of Technology, Hangzhou 310023, China; \\ fuyu@zjut.edu.cn \\ 2 College of Computer Science and Technology, Zhejiang University, Hangzhou 310058, China; \\ 13456918259@163.com \\ * Correspondence: 21121054@zju.edu.cn
}

Citation: Fu, Y.; Zhang, D.; Jiang, H. Students' Attitudes and

Competences in Modeling Using 3D

Cartoon Toy Design Maker.

Sustainability 2022, 14, 2176.

https://doi.org/10.3390/su14042176

Academic Editor: Eila Jeronen

Received: 15 December 2021

Accepted: 12 February 2022

Published: 14 February 2022

Publisher's Note: MDPI stays neutral with regard to jurisdictional claims in published maps and institutional affiliations.

Copyright: (c) 2022 by the authors Licensee MDPI, Basel, Switzerland. This article is an open access article distributed under the terms and conditions of the Creative Commons Attribution (CC BY) license (https:// creativecommons.org/licenses/by/ $4.0 /)$.

\begin{abstract}
With the rapid development of education and information technology, there has been an increasing focus on maker education, which emphasizes cultivating students' creative thinking and problem-solving ability. This paper presents our efforts to create a 3D cartoon toy design curriculum system that offers a playful and collaborative way to engage students with creation-based learning. It consists of a 3D modeling software and a series of 3D cartoon toy design courses. The former was developed according to students' cognitive characteristics and hands-on operation habits, and the toy design courses include activities such as hand-painting, computer modeling, pattern design, handcraft, and creative display. This 3D cartoon toy design course was preliminarily implemented in one kindergarten and two primary schools in Hangzhou, an eastern city in mainland China. A learning assessment of participating students was conducted upon completion of the course. Results show that (1) the initial attitudes of junior students towards learning 3D cartoon toy design were mainly influenced by their interests, whereas senior students paid more attention to turning their ideas into reality with the help of technical tools. (2) All students were highly successful at mastering foundational modeling concepts, but the junior students were less successful at mastering abstract modeling concepts. (3) The course was most successful in developing students' collaborative ability and content creation. (4) Additionally, teachers were successful at promoting a collaborative and communicative environment. Findings are discussed.
\end{abstract}

Keywords: 3D cartoon toy design; students' attitude; design maker competence

\section{Introduction and Objectives}

Nowadays, students are growing up with digital devices and innovative technologies that influence their way of learning as well as their daily lives [1-3]. A surging number of educators have been advocating the importance of maker education that incorporates information technologies [4,5]. In a traditional classroom, it is common for the teacher to talk and the student to listen [6]. However, maker education argues that a constructionist learning approach, where students learn by doing instead of by listening, is advantageous because it leads to more motivated students and a deeper understanding of the subject at hand $[5,7,8]$. Maker education transforms classroom activities from teacher-centered and didactic presentations to more interactive learner-centered, instruction emphasis transforms from fact memorization to the skills of problem solving and analysis, progress is evaluated by quality rather than quantity of output and criterion-referenced, and computers are used less for drill and practice activities and more for communication [9]. At the same time, maker education plays an important role in improving social and environmental sustainability [10].

Based on the concept of maker education, we developed a curriculum system of 3D cartoon toy design (Appendix A) and applied it in the practice courses of kindergartens and 
primary schools. On the basis of self-developed 3D design software, the course combines painting and handcraft to teach students how to design and make cartoon toys. The main contents of the course include designing and drawing cartoon images (hand-painting), using modeling software to build toy models in 3D space (computer modeling), using pattern design software to unfold 3D toy models into 2D patterns (pattern design), cutting pieces according to 2D patterns, hand-sewing and decorating cartoon toys (handcraft), and finally performing with cartoon toys (creative display). In this course, 3D modeling is a process from $2 \mathrm{D}$ to $3 \mathrm{D}$, pattern designing is a process from $3 \mathrm{D}$ to $2 \mathrm{D}$, and pattern design to sewing the toy is a process from $2 \mathrm{D}$ to $3 \mathrm{D}$ again. The two rounds of transformation from $2 \mathrm{D}$ to $3 \mathrm{D}$ and 3D to 2D deepen students' understanding of the relationship between 2D and 3D (Figure 1).

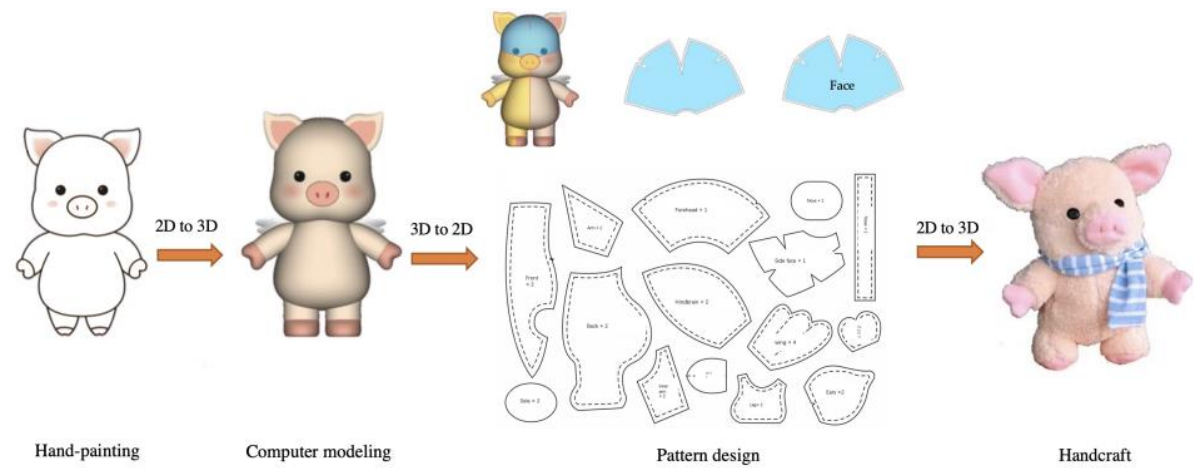

Figure 1. The process of designing and making cartoon toys.

The purpose of this study is to demonstrate how cartoon toy design and computer software can be used in the classroom and what students can learn with these tools. The goal of the 3D cartoon toy design course is not only to instill technical knowledge, but also to promote an interesting and cooperative learning environment. This paper applies the Positive Technological Development (PTD) evaluation framework proposed by Bers [11] to measure students' positive and interactive behaviors in the course. Specifically, this study raises the following research questions:

(1) What are the initial attitudes of students of different ages towards learning 3D design?

(2) What modeling concepts do students master after the 3D cartoon toy design course?

(3) How involved are students in different aspects of Bers' PTD evaluation framework in the 3D cartoon toy design course?

(4) What experience do teachers gain?

\section{Related Work}

\subsection{Maker Education for Students}

Although students are growing up in an increasingly digital environment, existing school curricula do not always focus on exploring the digital world until later elementary years. Only a few countries and regions have established clear policies and frameworks for introducing technology to early education [12-15]. Maker education is comprehensive quality education based on the integration of information technology and education, which aims to provide students with a suitable environment, resources, and opportunities for creation. Especially with the help of technical resources, the creative process can be integrated into the learning process so as to realize creation-based learning [5], cultivate a collaborative spirit, and develop problem-solving and innovation skills. This is also in line with the training requirements for innovative talents in the sustainable development process [16].

Most maker education courses focus on teaching and operation skills training of basic knowledge such as electronics, mechanics, mathematics, and computers, or complex skills training such as 3D modeling, manufacturing, circuit assembly, and programming [17-19]. 
Although these courses require students to solve problems using a variety of knowledge, they often focus on a certain technology or skills, but are less focused on comprehensive quality [20]. This study aims to use technology, social interaction, and interactive activities to help students construct their own understanding and enhance their comprehensive learning ability.

\subsection{Sketch-Based Modeling}

In recent decades, 3D design technology has been extensively studied in both academia and industry. With the software, users can design very complex and realistic 3D models. However, the existing software has mainly been developed for professional designers and the operations are too complicated and demanding for students. At present, there are very few modeling tools for students, such as Tinker, 123D Design, etc. This software simplifies the operations, but essentially follows the same workflow as professional software, so the design thinking still cannot be expressed quickly and effectively.

In product design, sketching is an important tool for design thinking and communication, and is usually the first step in creation [21]. Sketch-based modeling simplifies the traditional modeling approach, making it easier for students to build 3D models and providing them with an interesting and hands-on 3D model design tool. In our method, we realize an efficient and intuitive sketch-based modeling method by making use of the information extracted from the image. We use automatic alignment and deformation to replace the artificial selection to take more advantage of the input images, which makes it easier for students to produce personalized models (Appendix A).

\section{Methods}

In order to explore the full picture of the experience of the $3 \mathrm{D}$ cartoon toy design course, this study used a mixed-method research design that included data collected from a sample of students and their teachers [22]. The quantitative data collection mainly included students' scores from an attitude survey, from 3D modeling knowledge evaluation and behavior observation frequency, whereas the qualitative data mainly included teacher interviews and daily records. The process of qualitative data collection included teachers' opinions, feedback, and experiences, which could not be captured through solely quantitative measures. Considering that there were many unstable factors in the data collection from the sample population of students [23], the data collection method was more specific and simplified, and information was mainly obtained through one-to-one question-and-answer between researchers and students and classroom behavior observation.

\subsection{Participants}

We implemented this 3D toy design course in one kindergarten and two primary schools in Hangzhou, an eastern city in mainland China. A total of 93 students participated in this research (Table 1). The participating students aged from 6 to 12 years old, with an average age of 8.7 years. These students came from public and private schools. All the students consented to participate in this study. Five teachers from these schools also participated as collaborators in the research. In addition, we undertook informal interviews with co-teachers and assistant teachers whenever possible, seeking to gain valuable feedback that would help us to gain a fuller understanding of the course experience.

Table 1. Sample information.

\begin{tabular}{ccccc}
\hline & School & Grade & Sample Size & Age \\
\hline 1 & Kindergarten X & K-3 & 19 & $6-7$ \\
2 & Primary school Y & First grade & 18 & $7-8$ \\
3 & Primary school Y & Second grade & 20 & $8-9$ \\
4 & Primary school Z & Third grade & 19 & $9-10$ \\
5 & Primary school Z & Fourth grade & 17 & $11-12$ \\
\hline
\end{tabular}




\subsection{Instruments}

\subsubsection{Students' Attitude Survey}

To build rapport, before the course, the teachers asked about the students' hobbies, what they like and do not like at school, etc.- -a measure that we found was effective at putting the participants at ease. Next, each participant was provided with a short explanation of the course and asked to fill out a structured questionnaire to gauge their initial attitudes towards learning 3D design. The questionnaire was proposed on the basis of Pupils' Attitudes Towards Technology (PATT) [24-26], which was the mainstream instrument for ascertaining students' attitudes. It included six dimensions (i.e., Interesting course content, Group cooperation, Turning ideas into reality, Operating computers, Acquiring knowledge, Challenging content) with 18 items, and a five-point Likert scale (Strongly agree, Agree, Neutral, Disagree, and Strongly disagree) was used to assess their level of agreement with the statements in the questionnaire.

\subsubsection{D Modeling Knowledge Task}

The research group developed the "3D modeling knowledge" task to assess students" individual mastery of the 3D modeling software in terms of five functional modules: view, geometry, deformation, symmetry, and combinations. Students sat down with researchers one on one and were asked to help the researcher identify the way of modeling. For example, the researcher asked, "Which tool should I use if I want to model a top hat?" with the correct answer being the swing tool (Figure 2). After each question, students would indicate the function they thought was correct and their answers were recorded. Students received a point for correctly identifying one functional module, yielding scores ranging from 0 to 5 ( 0 means that no function module was correctly identified, and 5 means that all function modules were correctly identified).
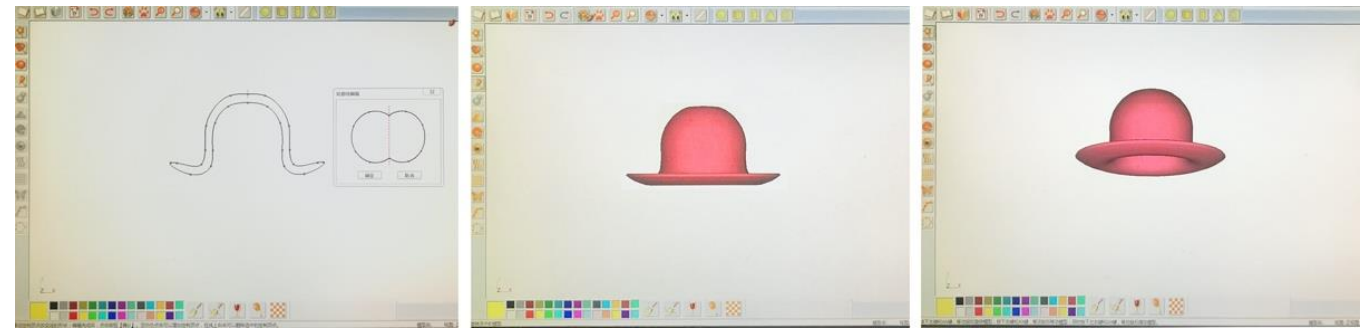

Figure 2. Using a swing tool to turn a curve into a 3D hat.

\subsubsection{Comprehensive Competency Assessments}

The comprehensive ability assessment was proposed on the basis of the Positive Technological Development (PTD) framework $[11,27,28]$. The goal of the 3D cartoon toy design course is not only to instill technical knowledge, but also to promote an interesting and cooperative learning environment. Therefore, we applied the PTD evaluation framework to measure students' positive and interactive behaviors and the evaluation index of such behaviors in the course.

The PTD-based assessment focuses on six positive behaviors (Six Cs): communication, collaboration, community building, content creation, creativity, and choices of conduct (i.e., positive behavioral choices). A checklist (Appendix B) assisted researchers in observing and recording the occurring frequency of behaviors related to the six Cs.

For each of the six Cs, researchers looked for specific behaviors and marked the frequency with which this behavior was observed during the $3 \mathrm{D}$ cartoon toy design course using a $1-5$ scale ( 1 = Never, 2 = Occasionally, 3 = Sometimes, $4=$ Often, $5=$ Always $)$. For example, for communication, researchers marked the frequency with which they observed behaviors such as students exchanging ideas with each other and students seeking help from and asking questions of one another. This assessment was performed by a trained researcher at the end of each lesson in the 3D cartoon toy design course. Raw scores were 
averaged into a mean score for each of the six Cs for each lesson. The scores for all lessons were then averaged to a mean composite score for each of the six Cs at the end of the course.

\subsubsection{Teacher Interviews and Daily Records}

After each 3D cartoon toy design lesson, the teachers were requested to complete a structured daily record to motivate them, reflecting on the success and challenges during the daytime lesson and describing the ways they adapted and personalized the course to meet their students' needs.

The teachers were also interviewed briefly by a researcher at the end of the class. The interviews were open-ended, with the purpose being to listen to the teachers' views and insights on the 3D cartoon toy design course and determine whether they needed any additional supports for the remainder of the research. Obtaining the practice and feedback on the 3D cartoon toy design course by means of teacher records and interviews was a direct way to learn the user's attitudes towards the course and could help understand the feasibility and potential problems in the course.

\subsection{Procedure}

The "design-make-display" flow was implemented as an 8-week extracurricular course in kindergarten and primary schools. Lessons were taught by research assistants and volunteer teachers from those schools (Figure 3). Volunteer teachers needed to have an art or information technology background, and they needed to participate in a one-day training on using the 3D modeling software. During this training, the teachers were also introduced to the 3D cartoon toy design curriculum and all assessment measures and activities they would need to implement through presentations and practical examples. There was one lesson per week. The teaching hour depended on the ages of the students, as younger students could only concentrate for a shorter period. In general, one lesson lasted approximately 1 to $2 \mathrm{~h}$. The contents were adjusted according to the characteristics of the students. For younger students, the teachers explained and practiced modeling knowledge through relatively simple 3D models. The teachers increased the complexity of explaining and practicing the models along with the increasing ages of the students. The cartoon toys designed and made by the students were as shown in Figure 4.
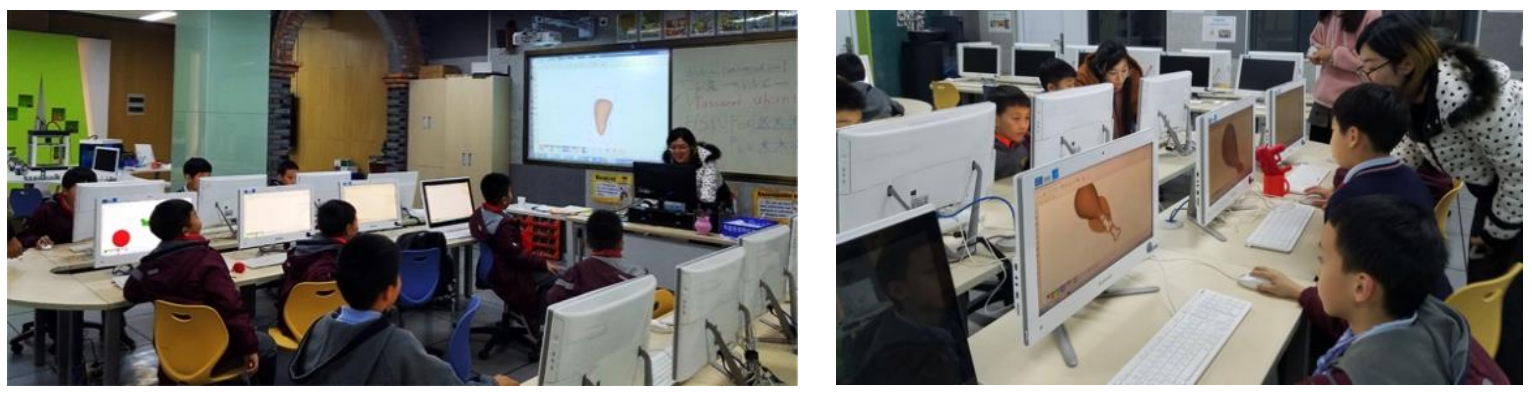

Figure 3. The 3D cartoon toy design course was taught by research assistants.
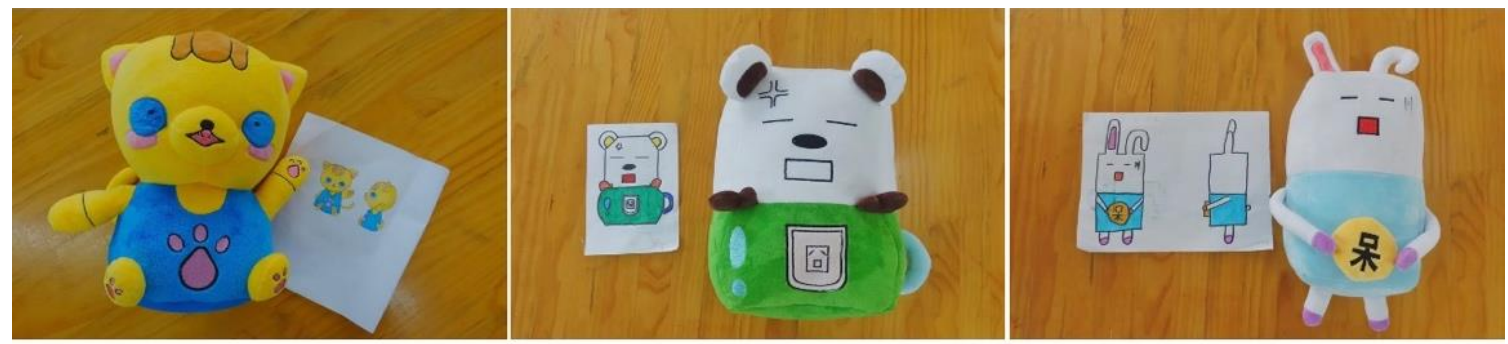

Figure 4. Cartoon toys designed and made by students. 


\subsection{Date Analysis}

Statistical analyses were conducted using SPSS version 22 (IBM Corp., Armonk, NY, USA). Principal analysis procedures included the calculation of descriptive and frequency statistics of the data. Cronbach's homogeneity coefficient alpha $(\alpha)$ was employed to determine the reliability and internal consistency of the attitude measurement section of the instrument. The Cronbach $\alpha$-value was acceptable $(\alpha>0.7)$ and reliable. The KruskalWallis $\mathrm{H}$ test was used to determine whether there were significant differences in the 3D Modeling Knowledge Task and Comprehensive Competency Assessment performance based on the students' grades. The results show that no significant differences were found based on the students' grade, indicating that all students were able to master the 3D modeling concepts similarly regardless of the grade they were in. The content analysis method was used to analysis the daily records and teacher interviews to corroborate the findings of the descriptive analysis [29]. The researchers first examined the data, revealed the pattern of codes, and then named the codes.

\section{Results}

The 3D modeling knowledge test and comprehensive competency assessment were calculated and compared between the five grades. On average, the students in this study successfully mastered the 3D modeling knowledge after completing this course, and their personal comprehensive competency was greatly improved. Typically, their performance increased by grade level, but not for each task.

\subsection{Students' Attitude}

By investigating the students' motivation to attend the course, the questionnaire results showed that the interesting attribute was the biggest reason attracting students to the 3D cartoon toy design course. After cross-analysis of the data, it was found that lower-grade students had relatively higher demand for experiential learning [30] such as interesting course content and group cooperation. With the increase in students' grade, their demand for skills such as turning ideas into reality and operating computers and for knowledge such as interesting and more challenging content rose, as shown in Figure 5.

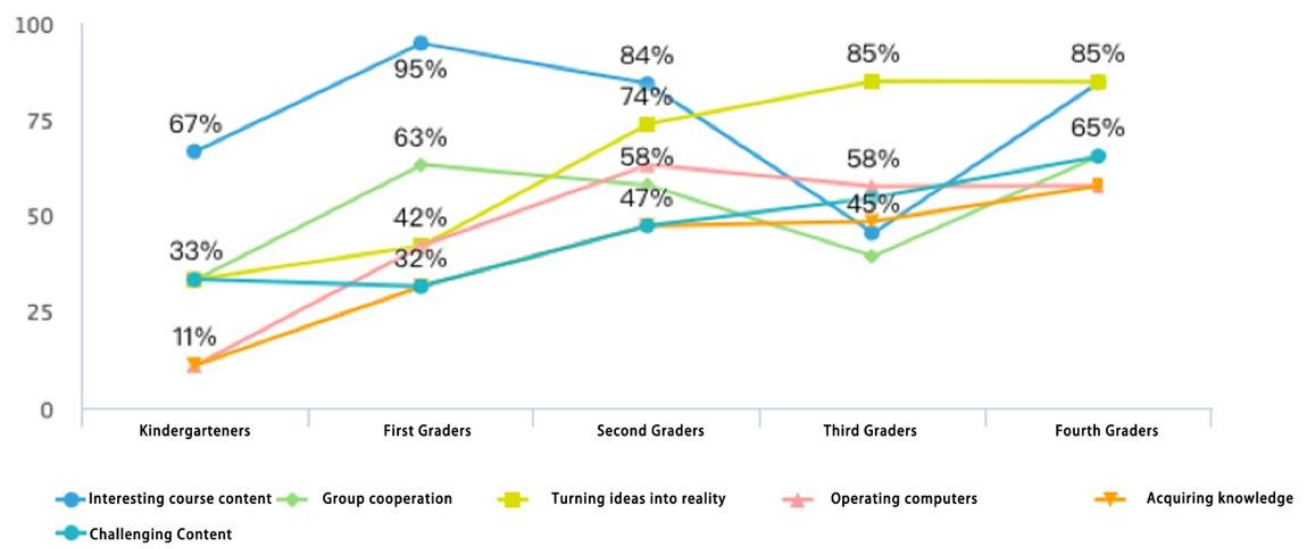

Figure 5. The motivation of students from different grades to attend the course.

\subsection{D Modeling Knowledge}

The students took a 3D modeling knowledge test after completing the course. Students received scores ranging from 0 to 5 based on whether they could correctly answer each of the five questions on the assessment. The overall mean scores from the 3D modeling knowledge test were very high for all grades, indicating that students had a good understanding of the function modules of the 3D modeling software. At the same time, the mean scores of students of different grades showed certain differences. It showed an increasing trend with an increase in age. As shown in Figure 6, kindergarten students had a good grasp of 
the modeling knowledge of view and geometry modules, whereas they had a relatively weak grasp of the modeling knowledge of other modules. Grade 1 and grade 2 primary school students had a relatively poor grasp of the modeling knowledge of deformation function modules. Although the teacher explained and demonstrated the deformation function in class, it was difficult for some junior students to correctly apply this function in practice. It was possible that the deformation function was too abstract for junior students to understand. Grade 3 and grade 4 primary school students had a relatively balanced grasp of the modeling knowledge of all modules.

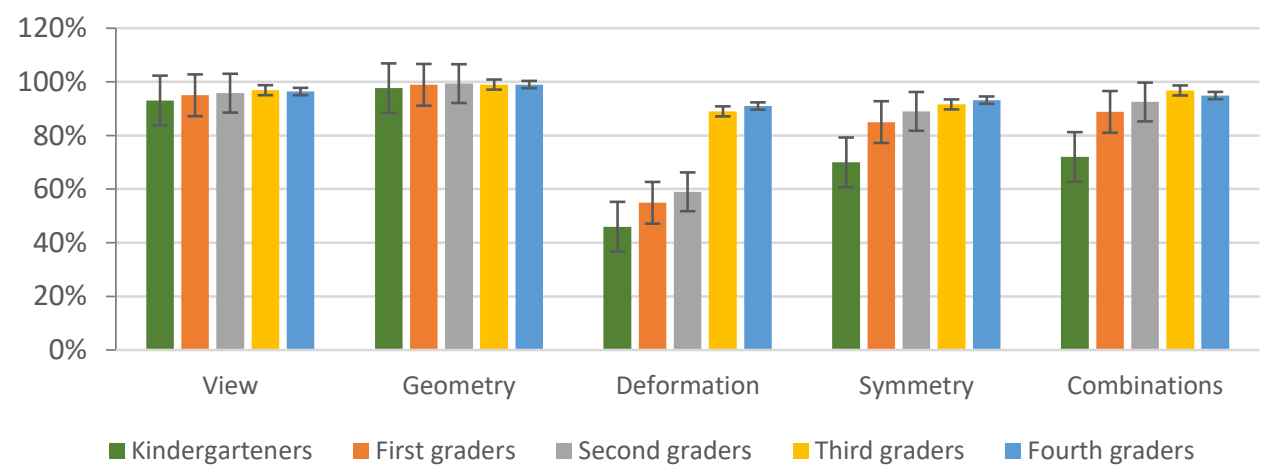

Figure 6. Percent of students able to correctly identify modeling software function modules.

\subsection{Comprehensive Competency Assessments}

The cumulative mean score for each of the six Cs of the PTD framework was calculated after the course. As shown in Figure 7, there was no significant difference between the five grades. The 3D cartoon toy design course had the best performance in developing students' collaboration (mean score 4.18). The course involved students discussing and completing the model together in the form of group cooperation. Especially in the process of model making and displaying, students borrowed tools or provided materials from each other more frequently, which was conducive to an improvement in their cooperation ability. For content creation (mean score 4.06), students also showed better performance in using software to build their own models and coping with problems in the modeling process. For communication (mean score 3.62), many students asked teachers or their classmates for help when they encountered problems, such as the specific use of a modeling function or the use of modeling materials. Therefore, they had an ideal mean score in communication. At the same time, most students were able to follow the classroom orderly and showed respect to other students and teachers (choices of conduct mean score 3.01), and they were also willing to share their work with the family (community-building mean score 2.98). Students' ability to apply technology in innovative ways had yet to be improved (creativity mean score 2.19). In general, students used the functional modules of modeling software in the way that the teachers taught them. They seldom independently developed other ways of using software functions. In the process of modeling, they mainly used the conventional materials produced by toys provided in the class, which had certain limitations on the expansion of materials.

\subsection{Teachers' Experience}

Based on the teachers' daily recorded feedback, they were usually able to successfully achieve their course goals. They chose to use a variety of guiding strategies when introducing complex concepts to the students. Some concept introduction strategies were directly from the 3D cartoon toy design course, whereas others were the teachers' own ideas. For example, teachers introducing a new concept in class by presenting a story, game, or song used a magic-like way to introduce the modeling tools (e.g., using the swing function to directly turn a curve into a 3D hat). Sometimes teachers used small group discussions and combined parental participation in the class. 


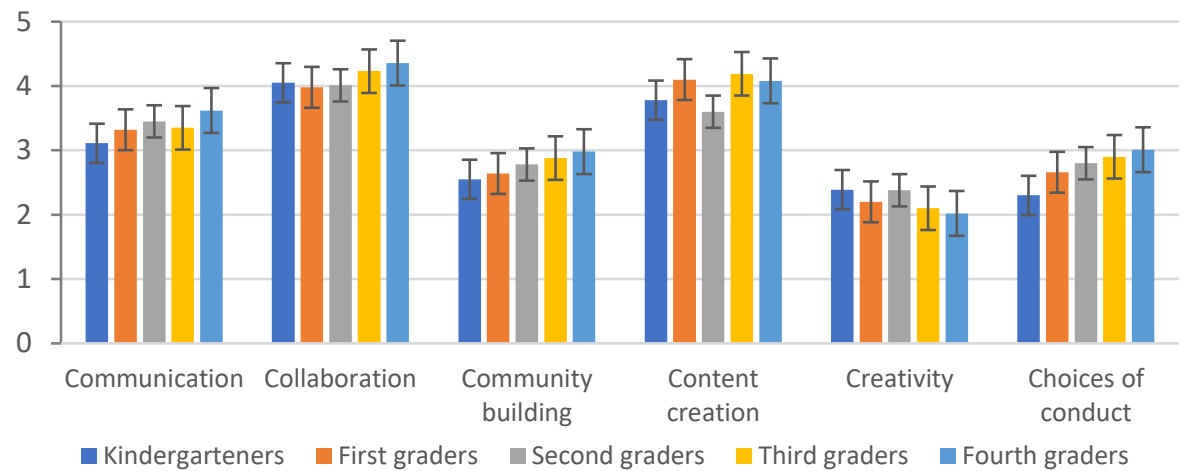

Figure 7. Cumulative PTD scores.

Teachers also proposed some suggestions for the adaptation and modification of the $3 \mathrm{D}$ cartoon toy design course to meet the needs of the students (Appendix C). In the classroom, the teachers were encouraged to teach in a flexible way; thus, they could adjust the course by adding or skipping some activities, or adjusting or changing the structure of the activities and the length of the course.

In interviews and daily records, the teachers shared their experiences related to the $3 \mathrm{D}$ cartoon toy design course, and Appendix D shows of the most frequent experiences mentioned by the teachers. From the perspective of the teachers, the course was successful; it stimulated students' interest, improved their self-study initiative, cultivated students' comprehensive competency and hands-on ability, and allowed students to develop collaboration and communication skills. It is well known that creativity is stimulating in the process of problem solving. Throughout the course, students acquired the social and individual capacity for "learning" that went well beyond the limits of conventional elementary education systems and met the need of sustainability [31]. That is, students actively participated in and promoted change, and were involved in problem-solving and action-taking for sustainability. Through the information given by the teachers in Appendix D, we can see students' curiosity and their attempts to solve problems in their own way and apply new materials were the main guiding factors stimulating the development of creativity. At the same time, the teachers also mentioned the mutual communication and cooperation between students in order to solve the problems in this process.

\section{Discussion and Conclusions}

This study collected data from students and teachers in China by quantitative and qualitative methods, and conducted a comprehensive assessment of the 3D cartoon toy design course through quantitative (students' attitude, modeling knowledge score, and comprehensive ability behavior frequency measurement) and qualitative data (teacher interviews and daily records). Unlike traditional classroom instruction, the maker course focused more on students' acquisition of diverse knowledge in practice and taught them a comprehensive set of practical skills, from design ideas to hand-making skills, that allowed them to learn to express ideas in different forms and inspire potential in the learning of skills. In the 3D cartoon toy design course, the students' ability to explore, discover, and construct their own understandings through the use of technology, social interaction, and interactive activities helped to enhance their learning.

The course began with cartoon image designing, teaching students first how to design cartoon toys, using 3D modeling software and pattern design software to design 3D models and 2D patterns, then hand-sewing toys, and finally allowing students to display their work in groups or as individuals. For senior students, relatively complex model cases in the explanation and practice of modeling concepts were used, whereas for junior students, we used relatively simple model cases in the explanation and practice of modeling concepts to meet the needs of different students. For different students, in addition to the adjustment of 
class time and course content, we also examined students' abilities in computer modeling to improve the teaching software.

This study mainly focused on the four issues mentioned in the introduction and led to the following conclusions through the experiments.

(1) The attitude scores demonstrated that the participation of junior students in the course was mainly influenced by the fun nature of the course, whereas the participation of senior students in the course was more because of their demand for technology.

(2) The students' 3D modeling knowledge scores demonstrated that all students were highly successful at mastering foundational modeling concepts. At the same time, the study provided preliminary evidence that 3D modeling software could be a useful and educational tool in the classroom.

(3) The PTD scores indicated that students in this study showed high engagement across PTD behaviors. Students not only had fun working during the course, but also showed positive learning outcomes.

(4) Results from the teachers' interviews and daily records indicate that the course was not only a positive experience for students, but also for them. Teachers were able to promote a collaborative, communicative, and creative environment in the course, and were able to make flexible adjustments to the course according to the actual classroom environment.

Practice results show that with the popularity of computer education, senior students generally had good basic capabilities of computer operation. Almost all students in second grade or above could operate computers for 3D modeling flexibly, whereas the computer operation ability of lower grade students varied. Students could basically turn their own hand-drawn manuscripts into a 3D model within the specified time. Because the modeling software in teaching was a sketch-based modeling technique, students quickly grasped the basic operations of modeling. Through the imitation and practice of cases, they mastered modeling skills from basic geometry to simple cartoon modeling after two courses. Based on feedback from the students, they were most interested in computer modeling-most students said that the modeling process was challenging but interesting. As for other aspects, students' preferences varied, but most students believed that the whole course was very interesting; they learned many new skills and they were very happy to design and make toys by themselves.

This study preliminarily verifies the usefulness of the 3D cartoon toy design course in students' education. The 3D cartoon toy design course is a participatory activity in which students can also obtain positive learning outcomes while gaining a fun experience. They were highly motivated and interested in using technological tools to learn. In kindergarten and elementary school, students can use technology such as modeling software to learn basic spatial geometry and gradually increase the complexity of learning as the grade increases. At the same time, students can also cultivate their studies of traditional subjects such as arts and crafts in the process of learning new technologies. The course encourages students to engage in problem-solving, self-direction, and collaborative work and improves students' comprehensive competency. Such learning helps students to translate skills, knowledge, and attitudes acquired through coursework into forms that can be applied in the working world and society at large.

\section{Limitations and Foresight}

The 3D cartoon toy design course is a brand-new course. So far, we have only carried out a preliminary exploration. With the in-depth application of the course, the course, software, and teaching all need to be continuously improved. Combining the maker space and comprehensive practice classes in kindergartens and primary schools, we plan to integrate the technical strength of the research team and the teaching experience of frontline educators to attract more students to participate in education of 3D cartoon design. In the future development, we hope to not only provide high-quality technical tools and 
courses, but also develop professional teachers to further enhance the influence of the course on students.

Some limitations of this study also need to be addressed in the future.

1. It takes too little time to complete the 3D cartoon toy design course in eight weeks, especially for kindergarten students, who cannot fully understand and practice the learning concept. Lower-grade students with slower behavior need more time to learn and practice than upper-grade students. Although they could complete the course content and tasks and produced their own cartoon toys, students in lower grades rarely made complex ones.

2. As an exploratory study, this paper applies only to a small sample population. Future research can expand the sample size to produce broader results.

3. The tools and courses can be adjusted and redesigned accordingly.

Two main additional future tasks can be considered:

1. The deformation function modules of the tool can be simplified to give students more convenience.

2. The demonstration of abstract modeling concepts can be strengthened to further educate students.

Author Contributions: Conceptualization, D.Z. and Y.F.; methodology, Y.F.; software, D.Z.; validation, Y.F. and H.J.; formal analysis, Y.F.; investigation, Y.F.; data curation, D.Z.; writing—original draft preparation, D.Z. and Y.F.; writing - review and editing, Y.F. and H.J.; visualization, H.J.; supervision, H.J.; project administration, D.Z.; funding acquisition, Y.F. All authors have read and agreed to the published version of the manuscript.

Funding: This research was supported in part by the Natural Science Foundation of Zhejiang Province of China under grant LQ20F020023, the Philosophy and Social Science Planning Fund Project of Zhejiang Province under grant 20NDQN260YB, the National Natural Science Foundation of China under grant 61702454, and in part by the Zhejiang Provincial Department of Education general scientific research program under grant GZ20491180009.

Institutional Review Board Statement: The study was conducted in accordance with the Declaration of Helsinki, and approved by the Institutional Review Board of Zhejiang University of Technology.

Informed Consent Statement: Informed consent was obtained from all subjects involved in the study.

Data Availability Statement: The data presented in this study are available on request from the corresponding author.

Acknowledgments: We are grateful to all the students and their parents in the participating school.

Conflicts of Interest: The authors declare no conflict of interest.

\section{Appendix A. Developing a 3D Cartoon Toy Design Curriculum System Appendix A.1. 3D Cartoon Design Software}

To enable students to explore and build 3D cartoon models easily, we developed 3D cartoon design software using the techniques of sketch-based search and composition, which maintains the usability and improves the speed and efficiency of modeling (citation will be added after anonymous review).

The core concept of our software is to build a 3D cartoon model on the basis of an image. The 3D modeling module takes a cartoon image with the target object as input (Figure A1a) and extract contours consisting of lines and graphics (Figure A1b). Students can draw a closed sketch line along the shape that he/she is interested in (Figure A1c). The system automatically matches the contour lines that the student is interest and adjusts the sketch line to snap the target shape in the image (Figure A1d). The aligned sketch line is then used to search for the best-matching part from the part database using the retrieval method (Figure A1e). Each part is categorized and stored with its boundary contours and shape descriptors with six views. The selected part is placed in the appropriate position 
with the proper orientation and size (Figure A1f) and automatically deformed to fit the target shape (Figure A1g). Following the same procedure, students can achieve a complex 3D model for their cartoon character after all parts are created (Figure A1h). After the 3D model is created, students can paint textures on the 3D object to finalize the modeling. In addition, the software interface is intuitive (Figure A2), and beginners who have no experience in 3D modeling can learn and master the operation in a short period of time.

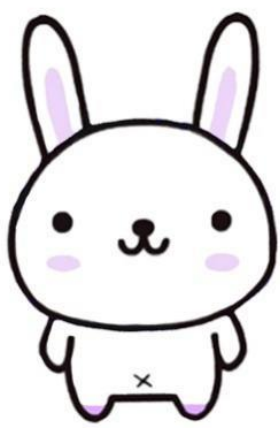

(a)

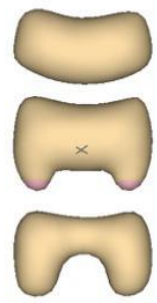

(e)

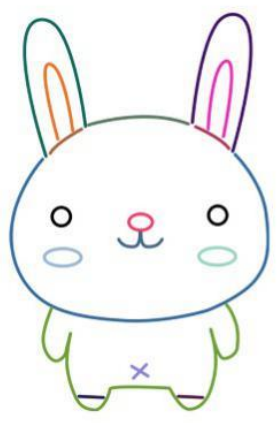

(b)

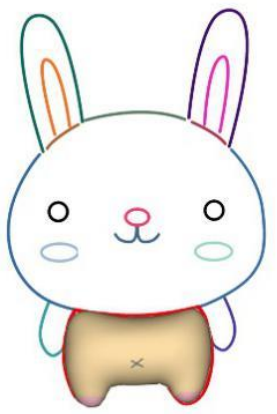

(f)

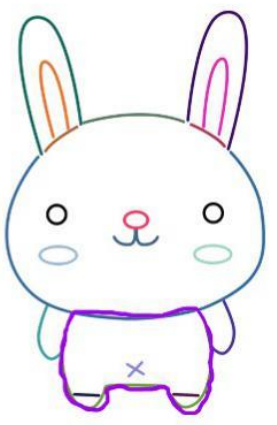

(c)

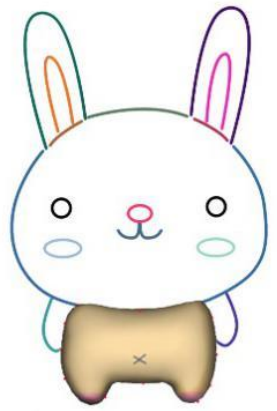

(g)

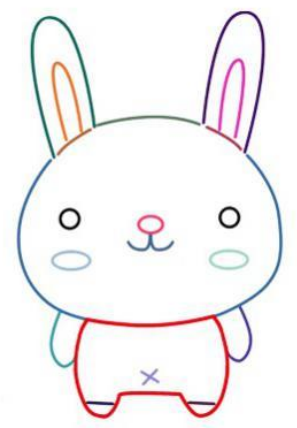

(d)

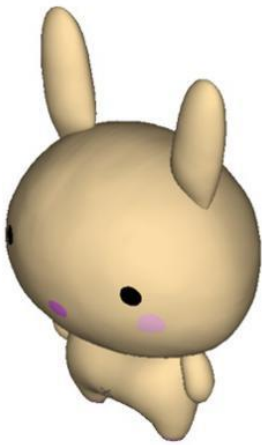

(h)

Figure A1. Process of 3D modeling: (a) cartoon drawing; (b) contour lines; (c) drawing a sketch line; (d) aligned sketch line; (e) part retrieval; (f) part placement; (g) part deformation; (h) final 3D model.

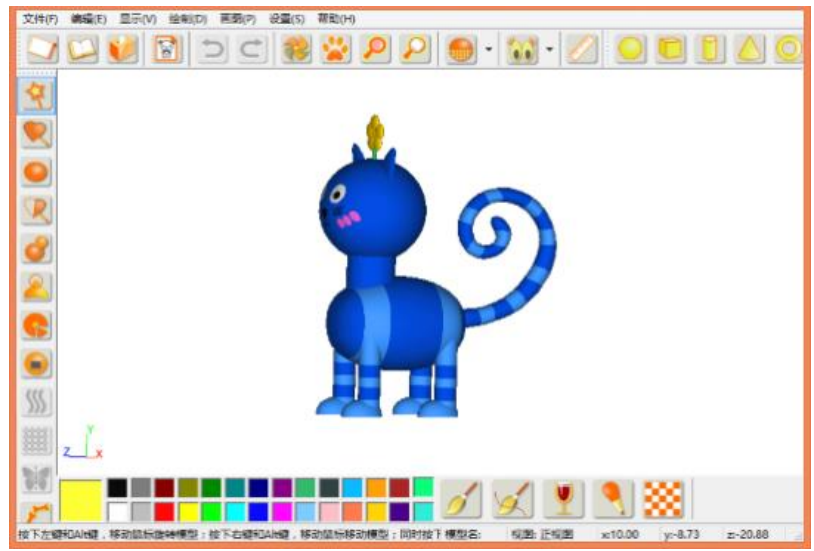

Figure A2. 3D modeling software interface.

The pattern design module of our software (Figure A3) generates 2D patterns of 3D models. It expands the 3D curved surface into a 2D plane automatically, thereby achieving $3 \mathrm{D}$ to $2 \mathrm{D}$ conversion (citation will be added after anonymous review). The resulting 2D pattern can be used to cut the fabric and complete the production of the cartoon toy. 
The workflow of the pattern design module is first, to draw the suture on the surface of the 3D toy model, then spread the 3D pattern onto the plane to automatically get a 2D pattern. Our method of automatic computer pattern design is easy to operate, and beginners can learn the basic operation in one or two hours.

Using 3D design software as an instructional tool in the course can help students cultivate their computer operation ability and 3D design ability, enhance their spatial imagination, help them understand the concept of basic geometry and image transformation (rotation, movement, and zoom) and the relationship between space and plane, and help them master the method of cartoon toy design. The learning of 3D software can also develop many other aspects of students' abilities. For example, early access to technical tools allows students to develop good hands-on skills and coordination skills, and promote cognitive, collaborative, and teamwork skills [9].

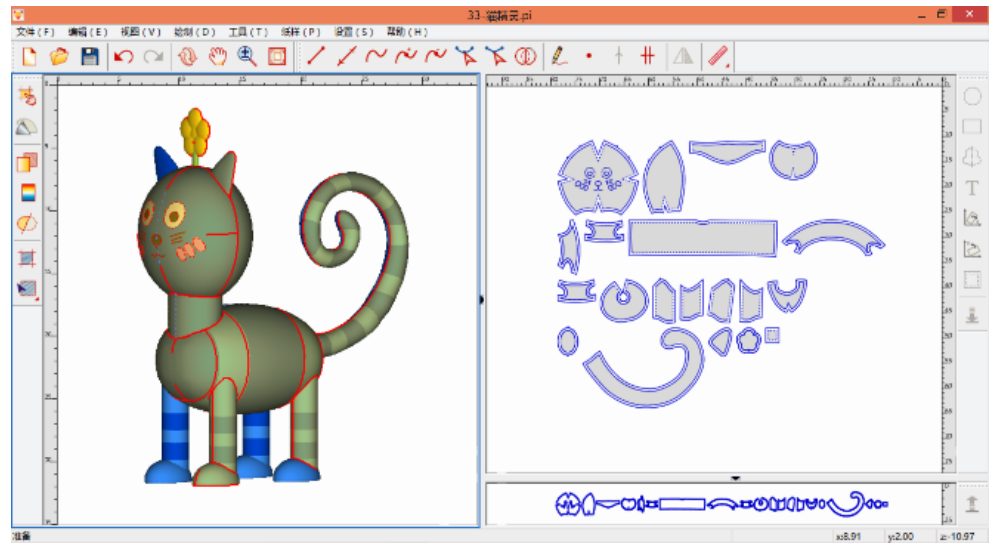

Figure A3. Pattern design software interface.

\section{Appendix A.2. 3D Cartoon Toy Design Course}

Because creativity is a skill that can be both taught and learned, the development of digital games as teaching or learning tools can stimulate students' learning motivation [32], improve their academic achievements [33], and cultivate their higher-order thinking skills [34], such as creativity, problem solving, collaboration, and critical thinking. Prensky [35] pointed out that creativity is stimulated in the process of problem solving. In addition, creative teaching refers to teaching techniques that help students learn new materials so that they can use knowledge to solve new problems [36]. Kiili et al. [37] argued that games meet the basic requirements of the learning environment and provide fascinating learning experiences for students. Some studies have found that dance, chess, rock climbing, and other activities help enhance students' learning ability.

This study intends to attract students' attention and enhance their motivation by integrating game elements into the course. The course adopts the teaching mode of "learning by doing" [38], which contains elements of imagination, curiosity, and challenge. It encourages students to solve problems in their own way, allows students to learn and create in an autonomous and open space, and provides free rein to their creativity with technical support and teacher support. It encourages children to transform their tacit knowledge into explicit knowledge [39] within the modeling process. The course integrates the process of technical production and artistic creation, which cultivates students' hands-on ability and creativity. In addition, whether individually or in groups, students can increase communication with peers or teachers in the process of problem solving and improve the possibility of problem solving through cooperation, a process that also cultivates students' teamwork and problem-solving skills.

The logic of the course is "design-make-display." "Design" is the most essential part of our course, which consists of three units: 2D hand-painting, 3D design and modeling, 
and pattern design. The hand-drawing course focuses on designing painting and teaching students to master the methods of cartoon image design and drawing. The 3D design and modeling course teaches students how to use 3D modeling software and build their own toy models in 3D space. Before making a cartoon toy, students need to learn to use the pattern design software to divide the $3 \mathrm{D}$ toy model into a $2 \mathrm{D}$ pattern. The "make" part includes a series of activities done by hand. When the pattern is printed, students can cut the pieces according to the pattern, hand-sew and decorate them, and finally complete their own cartoon toy design. The "display" part encourages students to share their work in a fun and creative way. Figure A4 shows the five units of our "design-make-display" cartoon toy design course.

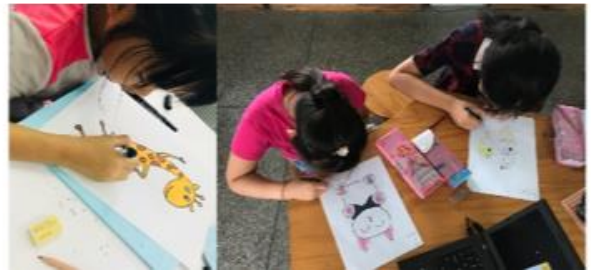

(a)

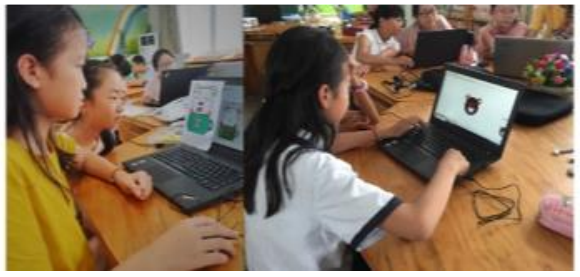

(b)

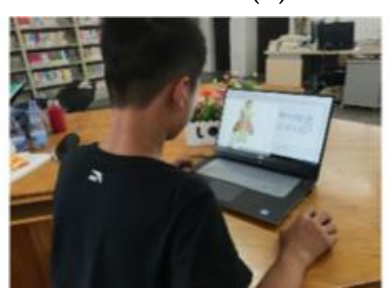

(c)

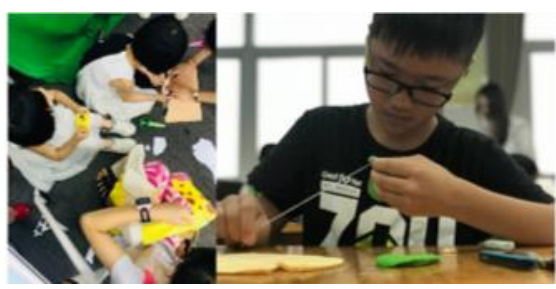

(d)

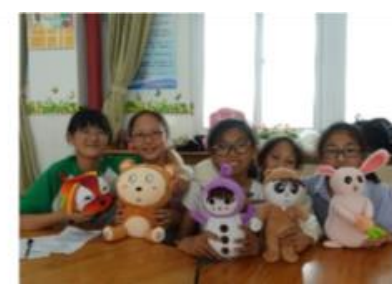

(e)

Figure A4. The example of the 3D cartoon toy design course process: (a) image design and drawing; (b) 3D design and modeling; (c) pattern design; (d) handcraft; (e) creative display.

- Unit 1: Inspire Creative Thinking: What Is the Cartoon Image Design?

Cartoon painting with pens and paper is a natural activity and an important experience for students to practice and express their creativity. During the first lesson of the course, students can explore the basic design process and method of cartoon imaging and learn how to design three views of the cartoon image.

On the basis of traditional art classes, it integrates the training of three-view painting in engineering drawing and infiltrates spatial thinking into the study of art classes to help students improve their ability to observe life and inspire their spatial imagination so as to pave the way for subsequent 3D teaching.

\section{- Unit 2: From 2D Drawing to 3D Modeling}

After students have mastered basic 2D cartoon image design methods, they are introduced to the concept of 3D modeling and use 3D modeling with our software.

In addition to increasing proficiency in computer operation, this unit helps students deepen their understanding of geometric knowledge in mathematics. Students can gain a basic understanding, from point, line, and plane to spatial geometry (balls, cones, cubes) during the modeling process, and deepen their understanding of mathematical concepts such as symmetry, rotation, and translation through software tools. Constructing a 3D model by sketching contours can greatly reduce the difficulty of modeling for students, improve the fun in the classroom, stimulate students' interest, and enhance their initiative in independent learning.

- Unit 3: Pattern Design: Exploring the Relationship Between Body and Surface

By exploring the connection between body and surface via pattern design, the students can think independently while learning new skills, such as exploring various expansion 
methods of the same geometric object and the influence of the length of the stitch on the shape of curved surface. The entire pattern design process is to enable students to have a more in-depth understanding of the transformation between body and surface to further expand their spatial thinking ability. We also encourage students to apply zero-waste design practices [40] to the setting of patterns to cut off the 2D pieces to compose the physical toys.

\section{- Unit 4: Handcraft}

In this "make" unit, students are exposed to a variety of fabrics and materials to understand their properties for practical application and are encouraged to adopt environmentally friendly materials. Students can master sewing skills and learn basic stitching skills in the course. At present, there are only a few kindergartens and primary schools in China with sewing classes, and only a small number of schools in large cities have specialized sewing classrooms. As one of the traditional forms of craftsmanship, sewing by hand is more suitable for students in terms of safety and operability than sewing machines. The course not only promotes traditional culture, but also enhances students' practical ability and environmental awareness. In addition to basic sewing, students unleash their creativity, such as making use of waste and using buttons and pins to decorate cartoon toys to make their own contribution to environmental sustainability.

- Unit 5: Interactive and Creative Display

Interactive teaching runs throughout the course. Teachers comment on students' work in each class, and students also conduct mutual evaluation. In this way, students compete and encourage each other. It changes the passive form of knowledge acquisition in the traditional classroom so as to inspire students' initiative and creativity in learning. As a comprehensive practical course, the course is not only designed to develop students' design and production skills, but also to develop their ability to express and collaborate. The course includes a form of group work that allows each student to independently complete their work while also helping others solve problems. In the final group presentation, students use their cartoon toys for creative display. Students can demonstrate their creativity multiple ways, such as through dramas and storytelling, which can not only enhance their oral expression skills and stage performance, but also enable them to experience happiness and satisfaction from cooperative performances.

\section{Appendix B}

Table A1. Six Cs and explanations.

\begin{tabular}{ll}
\hline Six C's & Definition \\
\hline Communication & $\begin{array}{l}\text { Students exchange ideas with each other. } \\
\text { Students seek help and ask questions. }\end{array}$ \\
\hline Collaboration & $\begin{array}{l}\text { Students work with others and willingly cooperate on a shared task. } \\
\text { Students borrow materials from or provide them to each other. }\end{array}$ \\
\hline Community building & $\begin{array}{l}\text { Students volunteer to share their work with others. } \\
\text { Students enhance the quality of their relationship with others. }\end{array}$ \\
\hline Content creation & $\begin{array}{l}\text { Students use a computer application to create content. } \\
\text { Students debug problems in their work. }\end{array}$ \\
\hline Creativity & $\begin{array}{l}\text { Students use a variety of materials for their work. } \\
\text { Students use technology in creative ways. }\end{array}$ \\
\hline Choices of conduct & $\begin{array}{l}\text { Students follow classroom rules. } \\
\text { Students respect other students and teachers. }\end{array}$ \\
\hline
\end{tabular}




\section{Appendix C}

Table A2. Examples of course adaptation and modification.

\begin{tabular}{ll}
\hline Types of Changes & Examples/Quotes \\
\hline Adding activities & $\begin{array}{l}\text { Before the cartoon image design, students are asked to show what kind } \\
\text { of toy image they want to design, and why they want to make such a toy. }\end{array}$ \\
\hline Skipping activities & $\begin{array}{l}\text { Some teachers' introductions and demonstrations of software functions } \\
\text { and material applications are deleted, enabling students to explore the } \\
\text { functions of software and the features of materials in hands-on operation. }\end{array}$ \\
\hline Adjusting activities & $\begin{array}{l}\text { The mutual evaluation among students is adjusted to mutual evaluation } \\
\text { between groups so that students can be more team-oriented in } \\
\text { competition. }\end{array}$ \\
\hline Adjusting time & $\begin{array}{l}\text { The time of the paper pattern design is shortened and the time of } \\
\text { handcraft course is increased. Students usually cannot complete the } \\
\text { sewing of the toy in two lessons. }\end{array}$ \\
\hline
\end{tabular}

\section{Appendix D}

Table A3. Frequent experiences mentioned by teachers.

\begin{tabular}{ll}
\hline Themes & Explanations \\
\hline Learning interest & $\begin{array}{l}\text { Students were very curious about the course content, and } \\
\text { eager to participate. They wanted to design and produce } \\
\text { their own toys. }\end{array}$ \\
\hline Autonomic learning & $\begin{array}{l}\text { Students actively explored how to use the software. } \\
\text { Students tried to make toy models with different materials. }\end{array}$ \\
\hline Hands-on ability & Students carefully sewed their toys and filled them. \\
\hline Collaboration and communication & $\begin{array}{l}\text { Students cooperated with each other. } \\
\text { Students actively participated in group discussions. }\end{array}$ \\
\hline
\end{tabular}

\section{References}

1. Danniels, E.; Pyle, A.; DeLuca, C. The role of technology in supporting classroom assessment in play-based kindergarten. Teach Teach. Educ. 2020, 88, 102966. [CrossRef]

2. Bers, M.U. Coding as a Playground: Programming and Computational Thinking in the Early Childhood Classroom; Routledge: New York, NY, USA, 2020.

3. Stéphan, V.-L.; Joaquin, U.; Soumyajit, K.; Gwénaël, J. Measuring Innovation in Education 2019: What Has Changed in the Classroom? Educational Research and Innovation; OECD Publishing: Paris, France, 2019.

4. Hsu, Y.-C.; Baldwin, S.; Ching, Y.-H. Learning through making and maker education. TechTrends 2017, 61, 589-594. [CrossRef]

5. Tian, Y. Maker education: Origin, connotation and possible path. Comp. Educ. Study 2016, 38, 22-28.

6. Richards, J.C. Teaching Listening and Speaking; Cambridge University Press: Cambridge, UK, 2008.

7. Taylor, B. Evaluating the benefit of the maker movement in K-12 STEM education. Electron. Int. J. Educ. Arts Sci. 2016, 2, 1-22.

8. Serholt, S. Breakdowns in children's interactions with a robotic tutor: A longitudinal study. Comput. Hum. Behav. 2018, 81, 250-264. [CrossRef]

9. Pierce, P.L. Technology Integration Intoearly Childhood Curricula: Where We've Been, Where We Are, Where We Should Go; University of North Carolina: Chapel Hill, NC, USA, 1994; p. 65.

10. Millard, J.; Sorivelle, M.N.; Deljanin, S.; Unterfrauner, E.; Voigt, C. Is the maker movement contributing to sustainability? Sustainability 2018, 10, 2212. [CrossRef]

11. Bers, M.U. Designing Digital Experiences for Positive Youth Development: From Playpen to Playground; Oxford University Press: New York, NY, USA, 2012.

12. Weng, J.; Li, H. Early technology education in China: A case study of Shanghai. Early Child Dev. Care 2020, 190, 1574-1585. [CrossRef]

13. Sullivan, A.; Bers, M.U. Robotics in the early childhood classroom: Learning outcomes from an 8-week robotics curriculum in pre-kindergarten through second grade. Int. J. Technol. Des. Educ. 2016, 26, 3-20. [CrossRef]

14. Otterborn, A.; Schönborn, K.; Hultén, M. Surveying preschool teachers' use of digital tablets: General and technology education related findings. Int. J. Technol. Des. Educ. 2018, 29, 717-737. [CrossRef] 
15. Johansson, A.-M. Examining how technology is presented and understood in technology education: A pilot study in a preschool class. Int. J. Technol. Des. Educ. 2021, 31, 885-900. [CrossRef]

16. Davis, J. Revealing the research 'hole' of early childhood education for sustainability: A preliminary survey of the literature. Environ. Educ. Res. 2009, 15, 227-241. [CrossRef]

17. Zheng, Y.; Luyi, L.I. Connotation, characteristics and implementation path of K- 12 learning by making in the USA. Open Educ. Res. 2014, 20, 42-49.

18. Maosheng, Q. The Application of Maker Education in Primary School Mathematics. China J. Multimed. Netw. Teach. 2020, 4, 30-40.

19. Hatisaru, V. Draw a mathematics classroom: Teaching and learning practices through the eyes of students. Math. Sch. 2021, 50, $4-8$.

20. $\mathrm{Hu}, \mathrm{Z}$. Middle school maker education curriculum development-Take the App Inventor as an example. Prim. Middle Sch. Inf. Technol. Educ. 2016, 2, 59-62.

21. Srinivasan, A.; Lee, B.; Henry Riche, N.; Drucker, S.M.; Hinckley, K. InChorus: Designing consistent multimodal interactions for data visualization on tablet devices. In Proceedings of the $2020 \mathrm{CHI}$ Conference on Human Factors in Computing Systems, Honolulu, HI, USA, 25-30 April 2020; pp. 1-13.

22. Bers, M.U.; Ponte, I.; Juelich, C.; Viera, A.; Schenker, J. Teachers as Designers: Integrating Robotics in Early Childhood Education. Inf. Technol. Child. Educ. Annu. 2002, 2002, 123-145.

23. Abrar, M.; Sidik, E.J. Analyzing ethical considerations and research methods in children research. J. Educ. Learn. (EduLearn) 2019, 13, 184-193. [CrossRef]

24. Ankiewicz, P. Perceptions and attitudes of pupils towards technology: In search of a rigorous theoretical framework. Int. J. Technol. Des. Educ. 2019, 29, 37-56. [CrossRef]

25. Svenningsson, J.; Hultén, M.; Hallstrm, J. Understanding attitude measurement: Exploring meaning and use of the PATT short questionnaire. Int. J. Technol. Des. Educ. 2018, 28, 67-83. [CrossRef]

26. Ardies, J.; De Maeyer, S.; Gijbels, D. Reconstructing the Pupils Attitude towards Technology-survey. Des. Technol. Educ. 2013, 18, 8-19.

27. Chau, C.L. Positive technological development for young children in the context of children's mobile apps. J. Chem. Inf. Modeling 2014, 140, 3624692. [CrossRef]

28. Sullivan, A.; Bers, M.U. Dancing robots: Integrating art, music, and robotics in Singapore's early childhood centers. Int. J. Technol. Des. Educ. 2017, 28, 325-346. [CrossRef]

29. Hsieh, H.-F. Three Approaches to Qualitative Content Analysis. Qual. Health Res. 2005, 15, 1277-1288. [CrossRef] [PubMed]

30. McCarthy, M. Experiential learning theory: From theory to practice. J. Bus. Econ. Res. 2010, 8, 131-140. [CrossRef]

31. Easton, P. Adult Education and Social Sustainability: Harnessing the "Red Queen Effect". Convergence 2007, 40, 171-185.

32. Bakker, M.; van den Heuvel-Panhuizen, M.; Robitzsch, A. Effects of playing mathematics computer games on primary school students' multiplicative reasoning ability. Contemp. Educ. Psychol. 2015, 40, 55-71. [CrossRef]

33. Hsiao, H.S.; Chang, C.S.; Lin, C.Y.; Hu, P.M. Development of children's creativity and manual skills within digital game-based learning environment. J. Comput. Assist. Learn. 2014, 30, 377-395. [CrossRef]

34. Hwang, G.-J.; Wu, P.-H.; Chen, C.-C. An online game approach for improving students' learning performance in web-based problem-solving activities. Comput. Educ. 2012, 59, 1246-1256. [CrossRef]

35. Prensky, M. Digital game-based learning. Comput. Entertain. (CIE) 2003, 01, 21. [CrossRef]

36. Dochshanov, A.; Tramonti, M. Re-making Classroom Borders with TINKERING Approach. In Proceedings of the International Pixel Conference-New Perspectives in Science Education, Florence, Italy, 22-23 March 2018.

37. Kiili, K.; Freitas, S.D.; Arnab, S.; Lainema, T. The design principles for flow experience in educational games. Procedia Comput. Sci. 2012, 15, 78-91. [CrossRef]

38. Anzai, Y.; Simon, H.A. The theory of learning by doing. Psychol. Rev. 1979, 86, 124-140. [CrossRef] [PubMed]

39. Silby, A.; Watts, M. Making the tacit explicit: Children's strategies for classroom writing. Br. Educ. Res. J. 2015, 41, 801-819. [CrossRef]

40. Carrico, M.; Kim, V. Expanding zero-waste design practices: A discussion paper. Int. J. Fash. Des. Technol. Educ. 2014, 7, 58-64. [CrossRef] 